\title{
Relevancia de los Manuscritos de 1844 en el pensamiento de Marx: Alienación y trabajo enajenado
}

Sección ESTUDIOS

RECIBIDO: $15 / 08 / 2021$

APROBADO: 15/10/2021

PUBLICADO ONLINE: 30/12/2021
Antonio Romero Reyes

Universidad Nacional Mayor de San Marcos

luis.romero1@unmsm.edu.pe

https://orcid.org/0000-0001-7010-5658

\section{RESUMEN}

La década de los años 40 del siglo XIX fueron años vitales en la maduración del pensamiento así como en la biografía intelectual de Karl Heinrich Marx. Los Manuscritos económico-filosóficos de 1844 formaron parte de un gran esfuerzo para fundamentar una episteme propia y original; y el presente trabajo pretende justamente rescatar, revalorar y reconstituir tales manuscritos en el conjunto del pensamiento de Marx'.

Se concentra la atención en el tema de la alienación y/o del trabajo enajenado, lo que es abordado desde varios ángulos: el núcleo duro de la crítica social del joven Marx; los sentidos marxianos del trabajo enajenado; el fundamento de una sociología crítica del capitalismo; todo ello en el marco de los mismos Manuscritos.

PALABRAS CLAVE: Manuscritos de 1844, alienación, trabajo enajenado, capitalismo.

Relevance of the 1844 Manuscripts in Marx's thought: Alienation and alienated labor

\section{ABSTRACT}

The decade of the 1940s of the 19th century were vital years in the maturation of thought as well as in the intellectual biography of Karl Heinrich Marx. The economic-philosophical Manuscripts of 1844 were part of a great effort to establish a proper and original episteme; and the present work tries precisely to rescue, reassess and reconstitute such manuscripts in the whole of Marx's thought.

1 La presente contribución es un resumen de capítulo de una investigación teórica del autor, la cual se halla registrada en la Unidad de Posgrado de la Facultad de Ciencias Sociales, Universidad Nacional Mayor de San Marcos (Dictamen Directoral N²42-UPG-F.CC.SS-2019).

(c) Los autores. Este artículo es publicado por la Revista de Sociología de la Facultad de Ciencias Sociales, Universidad Nacional Mayor de San Marcos. Este es un artículo de acceso abierto, distribuido bajo los términos de la licencia Creative Commons Atribución 4.0 Internacional (CC BY 4.0) [https://creativecommons.org/licenses/by/4.0/deed.es] que permite el uso, distribución y reproducción en cualquier medio, siempre que la obra original sea debidamente citada de su fuente original. 
Attention is focused on the issue of alienation and / or alienated labor, which is approached from various angles: the hard core of the young Marx's social criticism; the Marxian meanings of alienated labor; the foundation of a critical sociology of capitalism; all this within the framework of the same Manuscripts.

KEYWORDS: Manuscripts of 1844, alienation, alienated work, capitalism.

\section{Introducción}

E I propósito principal del artículo consiste en realzar la importancia de los $\mathrm{Ma}$ nuscritos de 1844 en el conjunto de los trabajos de la época de juventud de Marx. Se descarta la tradicional división entre el Marx joven y el Marx maduro, y la clasificación más amplia que hace Althusser de todos sus trabajos (Althusser, [1965] 1985, pp. 25-26); desechándose asimismo la distinción entre "marxismo" y "premarxismo". Las consecuencias de esa división althusseriana fueron, entre otras, alienar a Marx de Marx y condenar a los Manuscritos del 44 a una pieza de museo. Frente a esta tradición, que tuvo consecuencias funestas en la práctica política y en el pensamiento de los diversos "marxismos", en el presente trabajo se busca reconstituir dichos manuscritos en el pensamiento totalizador de Marx, abordándolo como un pensamiento que justamente va atravesando por una serie de cambios, giros y rupturas; formando parte de un colosal despliegue de fuerzas para fundamentar una episteme propia y original que incluía a la filosofía, y como resultado también de una praxis vinculada con la época histórica que le tocó vivir.

Se concentra la atención en el tema de la enajenación y/o del trabajo enajenado en tres acápites: el núcleo duro de la crítica social del joven Marx; los sentidos marxianos del trabajo enajenado; el fundamento de una sociología crítica del capitalismo. Cierra el artículo con algunas conclusiones provisionales.

\section{El núcleo duro de la crítica social del joven Marx}

La alienación era el "factor decisivo" (Schaff, 1979), "la clave" (Rubel [1954] 1970), "el corazón" (Berlín, [1939] 2007) de una teoría crítica de la sociedad que Marx se propuso elaborar, al menos en sus fundamentos, habiendo partido de la primera revisión de los economistas clásicos; revisión que años después convertirá en el proyecto de crítica de la economía política.

El conjunto de los Manuscritos del 44 se desdobla en tres partes: el primer manuscrito (28 hojas, páginas I-XXVII) contiene una serie de elaboraciones sobre 
el salario, la ganancia del capital, la renta de la tierra y el trabajo enajenado (este último título es de los editores), en base a la lectura y análisis de los economistas clásicos; el segundo está dedicado a la propiedad privada y es el más incompleto (se conservaron las últimas 4 hojas, XL-XLIII), ya que una gran parte del mismo se perdió: es un manuscrito del cual Marx probablemente extrajo muchos folios "para utilizarlos en otros escritos" (Fernández, 1998, p. 98)²; el tercer manuscrito (42 hojas, I-XLIII, habiendo un salto en la numeración de dos páginas) reúne varios tópicos: propiedad privada y trabajo, propiedad privada y comunismo, necesidadproducción-división del trabajo, el tema del dinero (este último, junto con el prólogo, p. XXXIX-XLIII, formaban parte de la proyectada "Contribución a la crítica de la economía nacional"), y la crítica de la filosofía hegeliana ${ }^{3}$. La paginación corresponde al documento original, enumerado por Marx con números romanos (Marx, 1982a, p. 723, n. 194). A nivel de conjunto, Fernández (1998) llama la atención no solamente del carácter fragmentario de los manuscritos, sino también de la ausencia de "mediaciones en la argumentación" (ob. cit., pp. 114-115), lo cual obedecería —al menos en parte - al reordenamiento editorial de su contenido (Veraza, 2011, pp. 24-25).

Marx reconoce que la propiedad privada es tanto la causa (desde un punto de vista histórico) como la consecuencia (a nivel analítico) del trabajo enajenado. Como anota Sánchez (1980), lo importante es que con la propiedad privada "todo lleva la marca de la enajenación" (ídem, p. 86). Si bien Sánchez llama la atención sobre la fuerte influencia de Feuerbach sobre el pensamiento del joven Marx, en el contexto de los Cuadernos de París, es en el marco de los Manuscritos donde el mismo Marx hace descender el "ser genérico" y la "esencia humana" del cielo filosófico y antropológico, de raíces feuerbachianas, al mundo terrenal de las

2 Al respecto, un discípulo de Bolívar Echeverría postuló la siguiente hipótesis: "es posible que las partes extraviadas del 'Segundo Manuscrito' fueran utilizadas por Marx como base para redactar, en 1846, el capítulo primero de La ideología alemana. Así, una vez escrito este capítulo - que contendría una versión mejor formulada del asunto—, tal vez Marx habría desechado aquellas páginas faltantes" (Veraza, 2011, p. 27). El "asunto" se refiere a la génesis histórica de la propiedad privada capitalista, cuestión planteada por Marx en el primer manuscrito al final del pasaje sobre el trabajo enajenado. Para este mismo autor, en la reconstrucción que hizo de los tres manuscritos, solamente el primero era propiamente tal, el segundo constituía en cambio una 'investigación', mientras que el tercero contenía con conjunto de digresiones ('excursos') a dicha 'investigación'. Por su parte, tanto el Prólogo como el epígrafe sobre el dinero eran "ensayos de redacción final" que fueron interrumpidos por Marx (ídem, p. 23).

3 Los epígrafes del tercer manuscrito fueron puestos por los editores de la MEGA. Con respecto al tema del comunismo entendido como superación del trabajo enajenado y la propiedad privada, cf. Fernández (1998, pp. 107-111). Con relación a la filosofía hegeliana: "Si bien Marx ubica la teoría de Hegel y su dialéctica en el marco del análisis y de la racionalización de la sociedad burguesa, no trata de destruir la dialéctica de Hegel, y, más bien, coquetea con ella. Así tenemos que la crítica de Marx a Hegel en los Manuscritos de 1844 no está orientada a destruir la dialéctica de Hegel, sino que trata de utilizarla de manera formal y de interpretarla en el contexto de la crítica a la economía política" (Gillen, 2016, p. 87). 
relaciones económico-sociales y del trabajo enajenado, donde adquieren nuevas connotaciones (sin abandonar del todo a las anteriores).

Es indudable que la alienación en los Manuscritos del 44 está expresada mediante el trabajo enajenado, esta vez como una categoría social que le sirve a Marx tanto para el "análisis económico" que se despliega en el primer manuscrito, como para la crítica de la sociedad capitalista a través de la propiedad privada, en el tercer manuscrito (este trabajo centra la atención en el primer manuscrito). La clave en ambos manuscritos es la relación entre trabajo enajenado y propiedad privada, que se puede explicitar a través de los siguientes enunciados (premisas):

i) La economía política clásica "arranca del hecho de la propiedad privada. Pero no lo explica" (Marx, [1932] 1962, p. 62). En cambio, el punto de partida de Marx es la relación entre el obrero y el producto de su trabajo, un hecho "puramente económico" (ídem, p. 69); es decir, una "relación objetiva" (Schaff, 1979, p. 93) que es de separación: el producto generado no le pertenece al obrero.

ii) Se desprende de lo anterior que la propiedad privada es un concepto derivado"por análisis" del trabajo enajenado (Marx, [1932] 1962, p. 70), y de lo cual se sigue que: "[...] la Economía política se limita a formular las leyes del trabajo enajenado" (ibíd.).

iii) Del trabajo enajenado y de la propiedad privada, donde la segunda es consecuencia del primero, es posible entonces "desarrollar todas las categorías de la Economía política, y en cada una de ellas [...] descubriremos simplemente una determinada y desarrollada expresión de estos primeros fundamentos" (ídem, p. 71; énfasis original).

iv) A fin de proceder conforme a lo anterior, la condición es que "[...] sólo concibiendo el trabajo como la esencia de la propiedad privada podemos también penetrar, en su determinabilidad real, en el movimiento de la Economía política" (ídem, p. 99).

Los enunciados anteriores dan cuenta asimismo de una ruta metódica, donde el trabajo enajenado es el "concepto clave" en base al cual Marx profundiza en su interpelación a la economía política, convirtiéndolo en "el corazón del problema", es decir, la "contradicción mayor" entre la miseria social del obrero y la riqueza económica que genera (Althusser, 1985, pp. 128-129)4, el "mal profundo" del capitalismo

4 "[...] desde el principio, Marx afirma claramente su posición crítica respecto de la economía política, lo mismo con respecto de la filosofía. Su punto de partida en esta crítica no es de ninguna manera el'concepto' de trabajo alienado; su punto de partida es, por lo contrario, la observación práctica de la miseria obrera que 
(Cornú, [1934] 1965, p. 569). Ha habido, entonces, un generalizado mal entendido, así como más de una interpretación errónea, sesgada o interesadamente distorsionadora, sobre la alienación-enajenación y/o el trabajo enajenado en el análisis de esos conceptos, que se prolonga hasta la actualidad. ¿Dónde radica el malentendido o la confusión? En función de los enunciados anteriores, el malentendido radica en haber descuidado o inadvertido el cambio del sentido y de significación (contenido) que adquirían en el pensamiento de Marx las mismas palabras tomadas de Hegel y/o Feuerbach ${ }^{5}$; asimismo por el nuevo contexto en el que Marx las emplea, mediante su desmitificación (inversión) filosófica. Ya no se trata de la "alienación religiosa" feuerbachiana, del "hombre deshumanizado", del "hombre alienado", ni del "hombre mutilado", sino de la alienación social como un hecho concreto y práctico que hunde sus raíces en un sistema histórico o régimen de producción (el capitalismo). La enajenación deja de ser un hecho metafísico o religioso porque Marx la ha refundado sobre nuevas bases ${ }^{6}$. Quienes infravaloraron y descartaron -entre ellos Althusser y su escuela - el concepto de enajenación y de trabajo enajenado en Marx, por considerarlo de la misma naturaleza y contenido como aparece en Hegel y Feuerbach, nunca se percataron que la problemática de la alienación es radicalmente diferente en la crítica que hace Marx a la filosofía del Estado de Hegel, de la que emprendió a la economía política en los Manuscritos del 44.

Puede decirse, sin la menor sombra de duda, que el "análisis económico" de Marx en sus manuscritos le permitió detectar el tema del poder desde el inicio, ya no en el marco hegeliano sino desde un hecho "puramente económico"7. De ahí

crece en la misma medida en que crecen las riquezas que esta misma clase obrera produce" (Mandel, 1980, p. 180)

5 Otros conceptos filosóficos que, tomados de Feuerbach, fueron transformados por Marx hasta perder su sentido original, son entre otros, los de "extrañamiento", "esencia humana", "ser genérico" (Mészáros, [1970] 2006, p. 19).

6 Sánchez Vázquez lo remarca así: "Marx sitúa, pues, el fenómeno de la enajenación en un nivel estrictamente humano. Ciertamente, ya Feuerbach lo había trasladado desde el nivel suprahumano en que lo situaba Hegel al mundo del hombre. Pero en Feuerbach sigue siendo, como en Hegel, el nivel de la conciencia, del espíritu, si bien se trata del hombre en cuanto que como ser consciente, espiritual, crea un producto que le es ajeno, extraño. En Marx se trata de una actividad humana pero material, productiva, y la enajenación tiene por ello un carácter práctico." (Sánchez, 2003b, p. 97)

7 "La lectura del Esbozo engelsiano había revelado a Marx que la crítica de la filosofía política de Hegel no era suficiente para elaborar, a partir de la simple negación del Estado, esa teoría radical de la sociedad que pudiera'apoderarse' de las masas obreras y tornarlas conscientes del imperativo de una revolución social que las liberara de su alienación. En cuanto a la ética de Feuerbach, su defecto esencial consistía en considerar al hombre sólo en su existencia afectiva, sin insistir sobre sus relaciones con el cuerpo social, verdadera clave de todos los problemas humanos. Sin embargo, ¿no era la economía política - ciencia de la producción y de la riqueza materiales - la que ofrecía esa clave que no podía dar la especulación filosófica ni las doctrinas sociales, al menos tal como se presentaban en la época? ¿No era la economía política la única teoría válida en cuanto a las relaciones humanas en la sociedad burguesa, puesto que ella misma se presentaba abiertamente como la ciencia de la propiedad privada, admitida como el postulado de base y el objeto reconocido de todas 
que sea necesario dejar sentado que en los Manuscritos del 44 nos encontramos ante una noción del poder que ya no parte del "espíritu absoluto", en todo caso un poder que viene y se impone desde arriba, sino que es una noción nueva del poder que surge desde y junto con las relaciones de producción.

En los Manuscritos del 44 Marx ya se ha convencido - a través de la crítica de la filosofía hegeliana del derecho- que la raíz del poder capitalista, como poder estatal, había que buscarla en la base de la estructura social y la única "ciencia social" de la que disponía en ese momento para su indagación era la economía política; no había otra porque lo demás — según Rubel — eran "doctrinas sociales", y en todo caso las "ciencias sociales" aún se hallaban en estado de gestación (Wallerstein, 2003, pp. 3-36, esp. 12-16). Esto no debe desmerecer lo que Marx había avanzado antes (la crítica de la filosofía política de Hegel), pues al dejarla suspendida o interrumpida para cambiar de ruta (la crítica del Estado desde abajo) no significa que la abandonara del todo, ya que el plan, según el prólogo de los Manuscritos, consistía primero en presentar la crítica de las diferentes materias (derecho, moral, política, etc.) de manera separada e integrarlas después en una exposición "de conjunto"; proyecto para el cual a Marx no le alcanzó el tiempo ${ }^{8}$.

\section{Los sentidos marxianos del trabajo enajenado}

Son dos los "temas fundamentales" que le preocupan a Marx en los Manuscritos: trabajo enajenado y comunismo ${ }^{9}$. Es en los Cuadernos de París donde justamente el

sus investigaciones?" (Rubel, [1954] 1970, p. 97). El “Esbozo engelsiano” es el trabajo de Engels publicado en los Anales Franco Alemanes (Engels, [1844] 1962a).

8 La cuestión del Estado será retomada más de una década después, en la Introducción de 1857 al final del apartado sobre "El método de la economía política" (Marx, [1953] 1982b, pp. 29-30), formando parte del "primer plan estructural" de El capital, donde junto a los temas del comercio exterior y el mercado mundial serían desarrollados a nivel de esbozo (Rosdolsky, [1968] 1986, pp. 36-37). Estos tres temas, concebidos como secciones o capítulos, fueron suprimidos del plan primitivo — según Rosdolsky — en 1865 o 1866, junto a los del trabajo asalariado y la propiedad de la tierra, tal como se puede verificar en las cartas de Marx a Engels del 31 de julio de 1865 (Marx y Engels, 1970, p. 119), y de Marx a Kugelman del 13 de octubre de 1866 (Marx, 1975, pp. 45-47), donde da cuenta de su plan definitivo.

9 Son "temas que Marx asociaba estrechamente, mostrando que tanto la formación de la alienación como su supresión resultaban del desarrollo del sistema de la propiedad privada" (Cornú, [1934] 196, p. 569). Lo que sigue trata del trabajo enajenado (primer manuscrito). El tema del comunismo se encuentra en el tercero de los Manuscritos del 44, no siendo el objeto de atención de este trabajo. Es necesario aclarar lo afirmado por Cornú, en la cita anterior, mediante las propias palabras de Marx en los Manuscritos: "Cierto que el concepto del trabajo enajenado (de la vida enajenada) fue extraído por nosotros de la Economía política, como resultado del movimiento de la propiedad privada. Pero el análisis de este concepto revela que, aunque la propiedad privada aparezca como el fundamento, como la causa del trabajo enajenado, es más bien una consecuencia de éste, del mismo modo que los dioses no son, en su origen, la causa, 
trabajo enajenado aparece presupuesto por la propiedad privada, que constituye su fundamento, lo cual es remarcado por Sánchez (1980, p. 85). Es importante la distinción entre los dos conceptos (trabajo enajenado y propiedad privada) en términos teóricos de relaciones causa-efecto: cuándo y dentro de qué condiciones uno es consecuencia del otro. Esta relativa ambigüedad se puede resolver mejor cuando los conceptos son confrontados en la realidad histórico-concreta que se pretende explicar ${ }^{10}$.

Marx explica el trabajo enajenado en función de tres manifestaciones: 1) la enajenación del obrero con respecto a los productos de su trabajo; 2) la enajenación del trabajador en la actividad productiva; 3) la reducción del "ser genérico" del hombre a un simple medio de su existencia física ${ }^{11}$.

Varias son las ideas que giran alrededor de la enajenación del trabajo, o que forman parte de su contenido:

- El producto del trabajo es "trabajo materializado en un objeto"y esto equivale a decir también objetivación del trabajo ${ }^{12}$.

- La objetivación implica que el objeto producido ya no le pertenece al productor $^{13}$, porque conlleva su apropiación por el capitalista.

- Objetivación quiere decir también "pérdida del objeto", y este último (el objeto-mercancía, incluyendo la naturaleza transformada) se vuelve"ajeno", hostil o extraño para quien participó en su producción.

sino el efecto del extravío de la mente del hombre. Más tarde la relación se convierte en una relación de interdependencia." (Marx, [1932] 1962, p. 70)

10 En una conferencia inaugural de mediados de octubre de 2017, conmemorando los "25 Años de Marxismo Abierto", la socióloga política Ana Dinerstein, al abordar las relaciones entre explotación, expropiación y compulsión laboral, sostenía: "La propiedad privada de los medios de producción es una precondición de la relación laboral", donde la precondición aludida es un concepto más concreto (la propiedad de los medios de producción), y a renglón seguido: "La explotación existe desde el momento de la expropiación, la cual [...] nos niega la posibilidad de vivir independiente de la forma social dinero. Esta expropiación precede (metafóricamente hablando) a la compulsión a trabajar" (Dinerstein, 2017 , p. 9). En esta segunda cita, en cambio, la expropiación precede a la propiedad privada e implica una enajenación tanto material como subjetiva, ya que es una expropiación completa de la vida del trabajador(a): su humanidad y existencia social pasan a depender del dinero y a ser parte del mecanismo de reproducción del capital (dinero y capital son encarnaciones del valor abstracto).

11 En los Cuadernos de París, en el desglose del "trabajo lucrativo" (con el número 4), se dice que uno de sus componentes consiste en "el hecho de que al trabajador se le presenta el mantenimiento de su existencia como la finalidad de su actividad; de que su hacer sólo tiene para él la función de un medio; de que pone en acción su vida para ganar medios de vida" (Marx, [1932] 1980, p. 144).

12 En El capital la "objetivación del trabajo" será reemplazada por nuevas categorías: la "objetividad del valor" (que permite la igualdad de los trabajos humanos), el trabajo objetivado (en las mercancías), o el "trabajo muerto" (este último referido a los medios de producción).

13 Para evitar interpretaciones reduccionistas, la palabra "productor" incluye al obrero o a cualquier trabajador (hombre o mujer, joven o adulto, blanco o de color) que es empleado por el capital o cuyo trabajo forma parte de relaciones de producción, directa o indirectamente, capitalistas. 
- La "pérdida del objeto" convierte entonces al producto del trabajo en una "existencia externa", es decir, independiente.

- Dicha existencia externa enfrenta al trabajador en el mercado, en la forma de medios o instrumentos de trabajo y medios para el sustento físico (de él o ella y su familia).

En toda esta parte el trabajo es considerado un objeto (otra mercancía) que Marx diferencia de la humanidad del obrero o trabajador. Las consecuencias que extrae para la individualidad (el ser viviente) del trabajador son las siguientes:

- La objetivación lleva a la "privación de realidad" para el obrero o cualquier productor de mercancías, mientras que la apropiación conlleva "extrañamiento" $y$ "enajenación" (estos dos últimos términos equivalen a lo mismo)

- La objetivación anula y esclaviza la humanidad del trabajador. De su dependencia con relación a los instrumentos de trabajo y medios de vida, que se enfrentan a él en el mercado, proviene la condición de "servidumbre del obrero".

- Se desprende entonces la pobreza material y espiritual (el mundo interior) del trabajador. El obrero se pertenece cada vez menos a si-mismo y su vida le pertenece al objeto-mercancía que ha generado ${ }^{14}$. En suma, el obrero se auto enajena/es enajenado.

Ordenando todo lo anterior en una secuencia lógica, se sigue que:

$$
\text { Objetivación } \rightarrow \text { Pérdida del objeto } \rightarrow \text { Apropiación } \rightarrow \text { Enajenación. }
$$

De esta primera manifestación surge la objetivación como una expresión del trabajo enajenado, con lo cual se refiere a que la "objetivación del trabajo" es la contrapartida a la "enajenación del obrero". Por el lado del trabajo la enajenación es objetiva, mientras que por el lado de la humanidad del obrero la enajenación es subjetiva ${ }^{15}$.

La segunda manifestación se enmarca — como ya quedó dicho- en la producción, donde aparece una nueva noción de "trabajo": este es entendido como

14 "Todas estas consecuencias vienen determinadas por el hecho de que el obrero se comporta hacia el producto de su trabajo como hacia un objeto ajeno. En efecto, partiendo de esta premisa, resulta claro que cuanto más se mata el obrero trabajando, más poderoso se torna el mundo material ajeno a él que crea frente a sí, más pobres se vuelven él y su mundo interior, menos se pertenece el obrero a sí mismo. Lo mismo sucede en la religión. Cuanto más pone el hombre en Dios, menos retiene de sí mismo." (Marx, [1932] 1962, p. 64)

15 La distinción entre el carácter objetivo o subjetivo de la enajenación proviene de Schaff (1979, pp. 104-105). 
"actividad práctica humana", en la que el trabajador se relaciona productivamente con los instrumentos, materiales, insumos y medios de producción, todos los cuales son asimismo trabajo objetivado. Aquí también se advierte un desdoblamiento, esta vez entre el individuo y su trabajo como actividad práctica, de manera que mientras el obrero tiene que producir, el trabajo (la actividad) que realiza le resulta "externo" o "extraño". El efecto de este desdoblamiento ("autoenajenación" dice Marx) también es doble: la enajenación de sí mismo y la enajenación del trabajo como actividad. En el primer caso, el obrero siente que trabaja por obligación (su condición social lo empuja a esto), no está a gusto (todo lo contrario) y por tanto se halla "fuera de sí"; solo cuando deja de trabajar (cuando está con los suyos) el obrero - dice Marx — recupera su personalidad. En el segundo caso, así como el producto del trabajo no le pertenece (la enajenación de la cosa), lo mismo ocurre con su actividad productiva y, entonces, el "acto de producción" es la "enajenación activa", "enajenación de la actividad", "actividad de la enajenación", lo cual lleva al extrañamiento como algo inherente a la actividad de trabajar ${ }^{16}$. Surge, pues, un nuevo sentido de la enajenación, desde la esfera de la producción, como extrañamiento. Este extrañamiento de la propia actividad viene a ser otra manifestación de la enajenación, a nivel material u objetivo, mientras que se reserva la autoenajenación para la parte subjetiva.

La tercera manifestación se sitúa en el "hombre" (ser humano) genérico y su existencia individual, ya que habiendo mostrado cómo se evidencia conceptualmente la enajenación (en términos objetivos y subjetivos) con relación a los productos del trabajo y del trabajo como actividad práctica, en la circulación y producción de mercancías, era inevitable para Marx referir la misma cuestión al "hombre", pero esta vez al nivel de toda la sociedad (las relaciones sociales). En este contexto, en el concepto de "hombre" como "ser genérico" se integran, en la misma persona: cuerpo (fisiología, anatomía), naturaleza (organismo viviente, sexualidad, reproducción), ser espiritual (creencias, ideas, emociones, subjetividad) y ser humano

16 El "acto de producción" es "como una actividad ajena y que no le pertenece [al obrero], la actividad como pasividad, la fuerza como impotencia, la procreación como castración, la propia energía física y espiritual del obrero, su vida personal — pues la vida no es otra cosa que actividad - como una actividad que se vuelve contra él mismo, independiente de él, que no le pertenece" (Marx, 1962, p. 66). Con relación a esto, en El capital puede leerse lo siguiente: "[...] todos los métodos para desarrollar la producción se trastruecan en medios de dominación y explotación del productor, mutilan al obrero convirtiéndolo en un hombre fraccionado, lo degradan a la condición de apéndice de la máquina, mediante la tortura del trabajo aniquilan el contenido de éste, le enajenan — al obrero - las potencias espirituales del proceso laboral en la misma medida en que a dicho proceso se incorpora la ciencia como potencia autónoma, vuelven constantemente anormales las condiciones bajo las cuales trabaja, lo someten durante el proceso de trabajo al más mezquino y odioso de los despotismos, transforman el tiempo de su vida en tiempo de trabajo, arrojan su mujer y su prole bajo la rueda de Zhaganat del capital." (Marx, 1982c, pp. 804-805) 
(comportamientos, relaciones, actividad, socialidad, individualidad); pero que en el marco del estado económico (es decir, en régimen de propiedad privada), dichos componentes son segregados y separados, fraccionados del "ser genérico" (o de la "vida genérica") dejándolo convertido en un cascarón vacío (es decir, un ser que se somete/es sometido y se limita a obedecer), convertido para todo efecto práctico en un medio con el cual asegurar la "existencia individual" o conservar la "existencia física" (el obrero junto con su respectivo salario son el mejor ejemplo de esto mismo).

\section{El fundamento de una sociología crítica del capitalismo}

El cuadro 1 permite resumir no solamente todo lo que involucra la enajenación o el trabajo enajenado, sino que contiene asimismo lo que el filósofo húngaro István, ([1970] 2006) Ilamaba la "teoría de la alienación" del joven Marx; o los elementos germinales de "una teoría original de la sociedad" como sostenía el sociólogo y filósofo francés de origen austriaco Maximilien Rubel ([1954] 1970, p. 99), en el sentido de una teoría social crítica.

\section{Cuadro 1}

La enajenación de la existencia social

\begin{tabular}{|c|c|c|}
\hline Ser genérico & Existencia social (Hacer) & Formas de enajenación \\
\hline \multirow[t]{4}{*}{ Hombre, Mujer } & Ser humano & \multirow[t]{2}{*}{ Hombre y mujer enajenado } \\
\hline & Ser social & \\
\hline & Ser libre & \multirow[t]{2}{*}{ Hombre y mujer extrañados } \\
\hline & Ser consciente & \\
\hline \multirow[t]{5}{*}{ Trabajo } & Actividad vital & \multirow[t]{3}{*}{ Trabajo enajenado } \\
\hline & Actividad práctica & \\
\hline & Actividad productiva & \\
\hline & Actividad libre & \multirow[t]{2}{*}{ Trabajo extraño } \\
\hline & Actividad consciente & \\
\hline Vida genérica & Vida productiva & Vida extraña \\
\hline
\end{tabular}

Fuente. Marx ([1932] 1962: 62-72). Elaboración. El autor.

Como se puede apreciar, en el cuadro 1 se ha desagregado el "ser genérico" en tres componentes: hombre/mujer, trabajo y vida genérica; la existencia social, a su vez, contiene diversas formas según el ser genérico; y lo que transforma las distintas formas de la existencia social en expresiones o modalidades de enajenación es 
la propiedad privada; es decir, un poder ocultado e inexplicado por la economía política, un "Estado" dentro del Estado". Se enajena, por tanto, el ser genérico, así como el ser social; mejor dicho, toda la existencia social incluyendo la del "noobrero" (cf. Sánchez, 2003b, pp. 94-103). Visto de otro modo, las potencialidades de la existencia humana son anuladas y metabolizadas por el capital, a través de la propiedad privada, para someter el "poder-hacer" (Holloway, 2012, p. 60) a la sola función de generar valor abstracto (trabajo, mercancías, dinero).

La consecuencia de la enajenación del ser genérico es la enajenación del hombre o mujer consigo mismo y con respecto a otras personas y, por extensión, de la respectiva sociedad ${ }^{18}$. Mediante la enajenación entre unos y otros se busca dar cuenta de procesos sociales de aislamiento, discriminación, separación, distanciamiento social, rivalidad y otros similares, a nivel material y subjetivo. Se entiende entonces que, en este contexto, la competencia mercantil tiene como premisa básica la enajenación de actores-sujetos-agencias; competencia que está erigida en principio universal, siendo alentada desde sus primeros fundamentos por la economía liberal clásica y las escuelas posteriores; alimentando y promoviendo mediante leyes económicas (como la ley de Say) la reproducción de procesos de enajenación. También atañe a los procesos políticos. Por eso, la sociedad burguesa, occidental y cristiana nació necesariamente como sociedad enajenada.

Es importante no olvidar que toda la reflexión de Marx, así como la terminología alrededor del trabajo enajenado, sus ramificaciones y significaciones, se inspira no en Hegel sino en las lecturas que hizo de Feuerbach: La esencia del cristianismo y las Tesis provisionales (Stedman, 2018, pp. 157-159) ${ }^{19}$.

En los Manuscritos del 44 Marx se dedicó entonces a "precisar su nueva concepción materialista del mundo" (Cornú, [1934] 1965, p. 566)20, a nivel de "rasgos generales" (ídem, p. 568). Engels había acuñado por primera vez la expresión

17 "[El obrero] Al convertir su propia producción en su privación de realidad, en su castigo, y su propio producto en su pérdida, en un producto que no le pertenece, engendra con ello la dominación de quien no produce sobre la producción y el producto. Al enajenarse su propia actividad, hace que el otro, el extraño, se apropie la actividad ajena" (Marx, [1932] 1962, p. 70). No cabe duda que ese "otro" y "extraño" es el capitalista (su equivalente en un país"socialista" era el jerarca del partido, el burócrata o comisario político).

18 "En general, la tesis según la cual se le enajena al hombre su ser genérico significa que un hombre se enajena al otro y que cada uno de ellos se enajena al ser humano" (Marx, [1932] 1962, p. 68).

19 "[...] lo que más le entusiasmaba [a Marx] del enfoque de Feuerbach era la visión de la religión solo como instancia de un proceso más vasto y universal de abstracción. [...] Mediante la traducción inversa de las abstracciones a los fenómenos naturales e históricos de los que se habían derivado, era posible —o eso decía Feuerbach - llegar a'la verdad no encubierta, pura e inmaculada"' (ídem, p 161, n. 342).

20 "De Hegel, Marx toma la idea del devenir histórico del hombre. De Feuerbach, toma el materialismo, el hombre concreto y la fórmula humanismo = naturalismo. Pero su concepción propia es completamente diferente de la síntesis de estos elementos. Los rebasa de una manera original, inclusive cuando parece hablar de aquellos que inspiran su pensamiento" (Bottigelli citado por Mandel, 1980, p. 176, nota 1). 
"concepción materialista de la historia" en la reseña que hizo de la primera obra de economía política que publicó Marx en 1859: Contribución a la crítica de la economía política (Engels, [1859] 1962b, p. 184); volviéndola a utilizar en la nota preliminar a la edición de 1888 de su escrito sobre Feuerbach que tuvo mucho más difusión (Engels, [1888] 1980, pp. 353-354).

Se puede apreciar, entonces, el gran esfuerzo del joven Marx que lo puso ad portas de una nueva y revolucionaria concepción del mundo, donde los Manuscritos del 44 y la categoría del trabajo enajenado tuvieron un rol estelar y en modo alguno marginal. Si bien otros autores (biógrafos y estudiosos del pensamiento de Marx) han puesto este asunto sobre el tapete, no deja de ser importante reiterar o insistir que es imposible entender al Marx científico del materialismo, al Marx teórico del comunismo, ni al Marx crítico de la economía política, sin esa etapa previa y vital de su vida; como tampoco se pueden comprender a cabalidad las Tesis sobre Feuerbach y La ideología alemana sin los Manuscritos del 44 junto a los concomitantes Cuadernos de París, con relación a los cuales, y también con relación a los Grundrisse, el Prefacio de 1859 es la síntesis de toda la nueva concepción ${ }^{21}$.

En lugar de cometer el error de ver la trayectoria intelectual de Marx como un proceso de ruptura consigo mismo, hasta llegar al "Marx maduro", todos sus trabajos debieran verse -es la propuesta de Sánchez (2003a) - "como fases de un proceso continuo y discontinuo" (ídem, p. 133), una praxis ${ }^{22}$. Marx proporciona el ejemplo perfecto de un modelo de praxis, es decir, fusión de pensamiento y acción, que pugnó por superar y romper con el "pensamiento único" de su época (el idealismo alemán) y con el orden socioeconómico y político imperante, que le permitió alumbrar una visión alternativa de sociedad sobre las bases materiales de relaciones y luchas, así como una propuesta de liberación humana donde la realidad material no excluye a la subjetividad (primera tesis sobre Feuerbach). Si Feuerbach

21 Sin la "alienación social" — dice Rubel — "la obra científica y política de Marx perdería su coherencia y su significación profunda. De ninguna manera se trata de un capricho de juventud, del cual se dice con frecuencia que fue superado por su autor; por el contrario, se trata del fundamento mismo de toda su obra teórica y de toda su carrera de hombre de partido" (Rubel, [1954] 1970, p. 62).

22 "[...] Sólo después de haber llegado al Manifiesto, puede decirse que existe el marxismo como filosofía de la praxis; en modo alguno como filosofía acabada, pues siendo la praxis, por esencia, infinita e incesante, jamás podrá cerrarse el proceso de esclarecimiento teórico de ella. Por esto, sería más exacto decir que con el Manifiesto se constituye el marxismo como tal filosofía de la praxis y se inicia un proceso que no puede tener fin. En el Manifiesto se anudan los cabos de elementos que han ido dando un perfil definido a esta filosofía de la praxis."(Sánchez, 2003a , pp. 133-134) Esta conclusión de Sánchez Vázquez podría complementarse con la afirmación, sin riesgo de equivocación, de que una parte de esos cabos o eslabones teóricos provino sin ninguna duda desde el aporte de los Manuscritos del 44. 
"fue el purgatorio de la juventud del siglo XIX" (Heller, 1984, p. 97) ${ }^{23}$, se lanza sin ninguna soberbia la siguiente pregunta: ¿es posible que Marx, tanto el joven como el adulto, sea el "purgatorio" de la juventud en el siglo XXI? Se trata sobre todo de un Marx que enseña a interrogar la realidad (Batou, 2017).

\section{Conclusiones provisionales para poder atravesar el "purgatorio" del presente}

El recorrido, así como la reevaluación que se acaba de hacer de los Manuscritos, en torno al tema de la enajenación, permite sostener que Marx puso los cimientos de una teoría crítica de la sociedad; siendo necesario añadir que la enajenación (o alienación) debe ser un componente fundamental de dicha teoría crítica, así como lo fue para Marx en su crítica de la economía política. Este abordaje debe diferenciarse de la "sociología de la alienación", donde la alienación ha sido vinculada con historias clínicas de estados mentales psicopatológicos (p. ej. Gabel, 1970). La teoría crítica por construir tampoco es identificable con la "sociología crítica", pues esta última, por más crítica que sea, sigue siendo académica y ajustada a la camisa de fuerza de una disciplina.

Se habla aquí de teoría crítica en el sentido, más bien, de ciencia social históricocrítica, o una "ciencia de la sociedad" como reclamaba Rubel ([1954] 1970, p. 16) ${ }^{24}$. Es importante considerar también aquí el tercer criterio de demarcación de Dussel (2001, pp. 284-289) y el llamado de Wallerstein para "construir una ciencia social histórica" (Wallerstein, 1999, p. 277). Es necesario también diferenciar la teoría crítica de la sociedad (por construir) de la visión, histórica y filosófica, materialista

23 "Y no hay para vosotros otro camino hacia la verdad y la libertad sino el que discurre a través del Feuer-Bach. Feuerbach es el purgatorio del presente" (Marx citado por Heller, ibíd. y n.1). De esta cita se puede deducir que el purgatorio es el "presente" que hay que atravesar (o superar) para llegar a la "verdad", y para ello Feuerbach era el instrumento. En "la juventud del siglo XIX", además de Marx, la autora menciona a Engels, Kierkegaard, Wagner, Nietzsche, Chernishevski y Keller (ibíd.). La traducción literal de "Feuer-Bach" es "arroyo de fuego" (Heller, 1984, 98, nota del traductor).

24 En su biografía intelectual de Marx, Karl Korsch designa la sociología de Marx en términos de "teoría materialista de la sociedad" o "ciencia social socialista y proletaria" (Korsch, [1938] 1981, pp. 19-24). Frente al cientificismo de Comte, fundador del positivismo en sociología, y de Spencer, con su visión organicista de la sociedad, Korsch consideró a los filósofos sociales, políticos y economistas franceces e ingleses del siglo XVIII como "los fundadores clásicos de la teoría de la sociedad", correspondiendo con "la época revolucionaria de la burguesía", época en la que se inscribe también la dialéctica hegeliana (ibíd.) Es con relación al pensamiento revolucionario del s. XVIII que se enlazará, según Korsch, la ciencia social de Marx, que concibe "la sociedad burguesa como una organización histórica en todos sus rasgos y, por lo tanto, también históricamente perecedera" (ídem, p. 23). La postura de Marx frente a los primeros sociólogos de su tiempo, Comte y Spencer, se halla en las cartas que dirigió a Engels, el 7 de julio de 1866 y el 23 de mayo de 1868, respectivamente. 
del mundo; es decir, de lo que Marx y Engels expusieron en la Ideología alemana ${ }^{25}$. Se comprende también por qué Marx creyó necesario profundizar primero en la "anatomía de la sociedad civil", mediante la crítica de la economía política, antes de edificar una tal teoría crítica de la sociedad y por ende del Estado; en este último caso, sobre la base de retomar la crítica del Derecho y del Estado de Hegel que -como ya se sabe- dejó como un proyecto inacabado. En este sentido, quienes sostienen que Marx edificó una "teoría" de la sociedad de clases, contenida principalmente en el Manifiesto y/o en El capital, dicen una verdad a medias por incompleta ${ }^{26}$.

En su biografía de Marx el filósofo alemán Karl Korsch, reconocido junto con Lukács y Gramsci como uno de los principales teóricos del marxismo de los años 30, habría sido de los primeros - si no el único — en haber planteado la problemática relación entre marxismo y sociología, asunto que está asimismo planteado en los apéndices de su obra. En las dos primeras tesis del segundo apéndice, Korsch sostuvo que la "teoría marxiana", sea como crítica materialista o como crítica histórico-social de la economía política, es una teoría económica, lo cual constituye (tercera tesis) su principal limitación (Korsch, [1938] 1981, pp. 268, 269 y 270, respectivamente). En su opinión, solamente cuando el orden social capitalista sea derrocado y rebasado por un proceso social revolucionario, que lo sustituya por una socialidad basada en el control "consciente y planificado" de la producción, la crítica de la economía política emprendida por Marx en El capital podrá "ser conducida hasta su final" y dar paso a "una teoría y una práctica directamente sociales de los productores asociados" (ídem, p. 276) 27.

Marx dejó una obra monumental e inacabada al mismo tiempo, pero en esa inmensa obra puso los cimientos y erigió las vigas maestras en términos de categorías y relaciones categoriales desde sus determinaciones más simples, todas basadas en un método muy potente, desde donde es posible trazar las nuevas cartografías a fin de retomar, continuar y poder atravesar el "purgatorio" de este presente histórico.

25 Kohan da a entender que La ideología alemana es, sobre todo, una teoría crítica marxista de la ideología entendida como "falsa conciencia", la que es asimilada a una "concepción epistemológica" de la ideología, diferenciándola así de la "concepción sociológica" de Gramsci (Kohan, 2003, pp. 19-44).

26 Con relación al Manifiesto Comunista, Antonio Labriola sostuvo:"si fue tantas y tantas cosas como sedimento de ideas diversas reducidas por primera vez a unidad intuitiva de sistema, y como cosecha de gérmenes capaces de un largo desarrollo, no fue ni pretendió ser, ni el código del socialismo, ni el catecismo del comunismo, ni el vademécum de la revolución proletaria ... El comunismo crítico, en verdad, comenzaba apenas con el Manifiesto; tenía que desarrollarse, y en efecto se ha desarrollado. El conjunto de doctrinas que hoy se suele llamar marxismo no ha alcanzado realmente la madurez hasta los años 60 y 70 [del siglo XIX (AR)]." Labriola citado por Fineschi (2013, p. 86 n. 4)

27 Santella (2014) examina el contraste entre lo sostenido por Korsch en la obra biográfica y sus "tesis inéditas" en el apéndice, a fin de fundamentar la problemática relación entre economía y sociología en el "marxismo". 


\section{Bibliografía}

Althusser, L. ([1965] 1985). La revolución teórica de Marx (21ํed.) (M. Harnecker, Trad.) México, DF: Siglo XXI Editores.

Batou, J. (2017)."Marx en el siglo XXI: ¿Y si las preguntas contasen más que las respuestas?” Viento Sur, 97-107, https://vientosur.info/category/revista/vientosur-no-153/

Berlin, I. ([1939] 2007). Karl Marx. Su vida y su entorno. (R. Bixio, Trad.) Madrid: Aianza Editorial. Cornú, A. ([1934] 1965). Marx-Engels. Del idealismo al materialismo histórico. (P. Canto, M. Alemán, Trads.) Buenos Aires: Platina-Stilcograf.

Dinerstein, A. (2017). "Afirmación como Negatividad. Abriendo espacios para otra teoría crítica" (Conferencia Inaugural), www.academia.edu/35231800

Dussel, E. (2001). "El programa científico de investigación de Karl Marx. Ciencia social funcional y crítica". En E. Dussel, Hacia una Filosofía Política Crítica (págs. 279-301). Bilbao: Editorial Desclée de Brouwer.

Engels, F. ([1888] 1980). "Ludwig Feuerbach y el fin de la filosofía clásica alemana”. En C. Marx, F. Engels, Obras Escogidas (Vol. III, págs. 353-395). Moscú: Progreso.

Engels, F. ([1844] 1962a). "Esbozo para una crítica de la Economía política”. En C. Marx, F. Engels, Escritos económicos varios (W. Roces, Trad., págs. 3-24). México, DF: Grijalbo.

Engels, F. ([1859] 1962b). “La 'Contribución a la Crítica de la Economía Política', de Carlos Marx. En C. Marx, F. Engels, Escritos económicos varios (W. Roces, Trad., págs. 183190). México, DF: Grijalbo.

Fernández Buey, F. (1998). Marx (sin ismos). Barcelona: El Viejo Topo.

Fineschi, R. ([1999] 2013). “Karl Marx después de la edición histórico-crítica (MEGA2): Un nuevo objeto de investigación". Laberinto(38), 85-102, https://marxismocritico. files. wordpress.com/2013/09/38fineschi1.pdf

Gabel, J. (1970). Sociología de la alienación. (N. Fiorito, Trad.) Buenos Aires: Amorrortu.

Gillen, C. (2016). Las complejas relaciones entre Hegel y Marx. Lima: Horizonte.

Heller, Á. (1984). Crítica de la llustración. Las antinomias morales de la razón (G. Muñoz, J. I. López Soria, Trads.) Barcelona: Península.

Holloway, J. (2012). Acerca de la revolución. Buenos Aires: Capital Intelectual.

Kohan, N. (2003). El capital. Historia y método (una introducción). Buenos Aires: Universidad Popular Madres Plaza de Mayo, www.rebelion.org/docs/3318.pdf

Korsch, K. ([1938] 1981). Karl Marx. (M. Sacristán, Trad.) Barcelona: Ariel.

Mandel, E. ([1967] 1980). La formación del pensamiento económico de Marx. De 1843 a la redacción de El Capital (10a ed.) (F. González Aramburo, Trad.) México, DF: Siglo XXI.

Marx, C. ([1932] 1962). “Manuscritos económico-filosóficos de 1844". En C. Marx, F. Engels, Escritos económicos varios (W. Roces, Trad., págs. 25-125). México, DF: Grijalbo. 
Marx, C. (1975). Cartas a Kugelman. (G. Bartarelli, Trad.) La Habana: Instituto Cubano del Libro.

Marx, C. ([1932] 1980). Cuadernos de París [Notas de lectura de 1844] (2ed.) (B. Echeverría, Trad.) México, DF: Era.

Marx, C. ([1835-1845] 1982a). Escritos de juventud. (W. Roces, Trad.) México, DF: Fondo de Cultura Económica.

Marx, K. ([1953] 1982b). Elementos Fundamentales para la Crítica de la Economía Política (Grundrisse) 1857-1858 (2 ed., Vol. 1) (P. Scaron, Trad.) México, DF: Siglo XXI Editores.

Marx, K. ([1873] 1982c). El capital. Crítica de la economía política. Libro primero: El proceso de producción de capital ( $9^{\circ}$ ed., Vol. Tomo I/Vol. 3) (P. Scaron, Trad.) México, DF: Siglo XXI.

Marx, C.; Engels, F. (1970). "El capital" visto por su autor. México, DF: Grijalbo.

Mayer, G. ([1920] 1979). Friedrich Engels: una biografía. (W. Roces, Trad.) México, DF: Fondo de Cultura Económica.

Mészáros, I. ([1970] 2006). A Teoria da Alienação em Marx. (I. Tavares, Trad.) São Paulo: Boitempo.

Rosdolsky, R. ([1968] 1986). Génesis y estructura de El capital de Marx (estudios sobre los Grundrisse) ( $5^{\circ}$ ed.) (L. Mames, Trad.) México, DF: Siglo XXI.

Rubel, M. ([1954] 1970). Karl Marx. Ensayo de biografía intelectual. (S. Karsz, Trad.) Buenos Aires: Paidós, https://elsudamericano.files.wordpress.com/2013/02/rubel-maximilien-karl-marx-ensayo-de-biografia-intelectual-1957.pdf

Sánchez, A. ([1972] 1980). "Economía y Humanismo". En C. Marx, Cuadernos de París. [Notas de lectura de 1844] (B. Echeverría, Trad., $2^{\circ}$ ed., págs. 11-97). México, DF: Era.

Sánchez, A. ([1967] 2003a). Filosofía de la Praxis. México, DF: Siglo XXI.

Sánchez, A. ([1982] 2003b). El joven Marx: Los Manuscritos de 1844. México, DF: UNAM/La Jornada/ITACA.

Santella, A. (2014). "Economía y sociología en el marxismo de Korsch". IV Jornadas Internacionales de Investigación y Debate Político del CEICS. Buenos Aires, www. academia.edu/7333626/

Schaff, A. (1979). La alienación como fenómeno social. (A. Venegas, Trad.) Barcelona: Crítica.

Stedman, G. (2018). Karl Marx. Ilusión y grandeza. (J. Collyer, Trad.) Madrid: Taurus (libro en versión electrónica).

Veraza, J. ([1994] 2011). Los Manuscritos de 1844. Un discurso revolucionario integral. De cómo los escribió Marx y cómo leerlos en el siglo XXI. México, DF: Itaca, http://africando. org/ong/prensa-para-pensar/pdf-manuscritos-de-1844-discurso-revolucionariode-como-los-escribio-marx/ 
Wallerstein, I. ([1987] 1999). "Llamado a un debate sobre el paradigma”. En I. Wallerstein, Impensar las Ciencias Sociales. Límites de los paradigmas decimonónicos (S. Guardado, Trad., $2^{\circ}$ ed., págs. 257-277). México, DF: Siglo XXI.

Wallerstein, I. ([1996] 2003) (coord.) Abrir las Ciencias Sociales (7 ed.) (S. Mastrángelo, Trad.) México, DF: Siglo XXI/UNAM. 